\title{
Mapping Services at Two Nairobi County Primary Health Facilities: Identifying Challenges and Opportunities in Integrated Mental Health Care as a Universal Health Coverage (UHC) Priority
}

Manasi Kumar ( $\square$ manni_3in@hotmail.com )

University of Nairobi https://orcid.org/0000-0002-9773-8014

Vincent Nyongesa

University of Nairobi College of Health Sciences

Martha Kagoya

University of Nairobi College of Health Sciences

Byamah Brian Mutamba

Butabika Hospital: Butabika National Referral Hospital

\section{Beatrice Amugune}

University of Nairobi College of Health Sciences

\section{Neha Krishnam}

UW: University of Washington

\section{Grace Nduku Wambua}

VU: Vrije Universiteit Amsterdam

\section{Onesmus Gachuno}

University of Nairobi College of Health Sciences

\section{Shekhar Saxena}

Harvard University

\section{Primary research}

Keywords: Universal Health Coverage, WHO-AIMS, Primary Health Care, Mapping Health Services, Facilitators, Challenges, Integrated Care Model, Mental Health Integration, Peri-partum Depression

Posted Date: March 18th, 2021

DOl: https://doi.org/10.21203/rs.3.rs-311860/v1

License: (9) (1) This work is licensed under a Creative Commons Attribution 4.0 International License. Read Full License 
Version of Record: A version of this preprint was published at Annals of General Psychiatry on August 17th, 2021. See the published version at https://doi.org/10.1186/s12991-021-00359-x. 


\section{Abstract}

Introduction: We describe a facility mapping exercise conducted in two low-income/primary health facilities in Kenya to identify available service resources, cadres, and developmental partners as well as existing barriers and facilitators in the delivery of mental health services in general and specifically for peripartum adolescents in primary health care. We have tried to embrace the principles of integrating mental health services in primary care and keeping WHO mhGAP in mind. Additionally, primary care facilities' capacity is a major limiting factor for expanding universal health coverage in low- and middleincome countries.

Method and Measures: This study utilized a qualitative evidence synthesis through semi-structured facility services mapping and stakeholder interviews. Services-related data was collected from two facility in-charges using the Nairobi City County Human Resource Health Strategy record forms. Additionally, we conducted 12 key informant interviews (KIIs) with and clinical officers (Clinicians at diploma level), Nurses, Community Health Assistants (CHAs), Prevention of Mother-to-child Transmission of HIV Mentor Mothers (PMTCTMs), around both general and adolescent mental health as well as psychosocial services they offered. Using the World Health Organization Assessments Instrument for Mental Health Systems (WHO-AIMS) as a guideline for the interview, all KIl questions were structured to identify the extent of mental health integration in primary health care services. Interview transcripts were then systematically analyzed for common themes and discussed by the first three authors to eliminate discrepancies.

Results: Our findings show that health care services centered around physical health were offered daily while the mental health services were offered weekly through specialist services by the Ministry of Health directly or non-governmental partner. Despite Health care workers being aware of the urgent need to integrate mental health services into routine care, they expressed limited knowledge about mental health disorders, lack of trained mental health personnel, the need for more significant funding and resources to provide mental health services, and promotion of CMHS to treat mental health conditions in the primary care setting. Our stakeholders underscored the urgency of integrating mental health treatment, prevention, and well-being promotive activities targeting adolescents especially peripartum adolescent girls.

Conclusion: There is a need for further refining of the integrated care model in mental health services and targeted capacity building for health care providers to deliver quality services.

\section{Background}

In the 2019 World Health Report (1), the World Health Organization (WHO) reiterated that neuropsychiatric disorders pose a significant burden in low-and-middle-income countries (LMICs) and stressed the urgent need to address this burden through robust treatment, prevention, and promotion efforts. The report advocates for more excellent international and national investment in research and policy advancement to globally improve health services coverage, with priority to primary health care services (2). The World 
Health Organization's Assessment Instrument for Mental Health Systems (WHO-AIMS) (3) was developed explicitly for LMICs to evaluate crucial aspects of mental health systems through established data sets $(4,5)$. WHO-AIMS enables assessing the mental health systems, delivery, and support required for the vulnerable populations in primary health care (5).

In 2010, mental and substance use disorders were the leading causes of years lived with disabilities (YLDs) in Sub-Saharan Africa (SSA) with a total burden of $18.94 \%$ (6) and were projected to rise from 20 million to 45 million YLDs by 2050 (7). Previous publications such as the 1990 Global Burden of Disease (GBD) review also underscored the reality that the mental health burden increases in SSA and global LMIC contexts (8). In LMICs, resources are scarce and inadequately distributed $(9,10)$, as mental disorders receive as little as $1.6 \%$ of LMIC government health budgets and $0.4 \%$ development assistance for health $(11,12)$.

Mental illnesses in Kenya account for $4 \%$ of the significant health conditions, and this figure is commensurate with the global burden of disease estimates for mental disorders $(13,14)$. Despite mental health disorders becoming more prevalent in Kenya (15), there remains a disproportional provision of mental health services due to a deficiency of trained mental health professionals (3). The mental treatment gap is worsened by the limitation of resources resultant from low government budgetary allocation. From workshop proceedings published in 2016 (15), Kenya, with a total population of 47 million people has less than 500 trained mental health professionals comprising only one hundred psychiatrists, the majority of whom were based in Nairobi and twelve neurologists mainly working in private hospitals in urban settings $(15,17)$. A, established that there were no psychiatrists or psychologists in the county, with the two psychiatric nurses in service expected to serve a population of 1.2 Million people (18). Further, mental illness is thought to be a result of witchcraft, thus altering healthseeking behaviors (19). Stigma, discrimination, lack of accurate information about mental health conditions, where to seek services, and economic challenges that make it difficult for patients to afford consultation, medication, and rehabilitative services are some of the barriers to access mental health services (20).

In 2008, the WHO Mental Health Gap Action Programme (mhGAP) was launched to expedite country-level policy and programs towards closing the treatment gap. The program created a Framework for Country Action, which provided countries with recommended steps to scale up their interventions and treatment for mental, neurological, and substance abuse disorders (21-23).

Through the Kenya Essential Package for Health (KEPH) (24), the Kenyan government has divided the health care system into six levels that include: Level 1 Community Units; Level 2 Dispensaries and Clinics; Level 3 Health Centers; Level 4 Sub-County Hospitals; Level 5 County Hospital; Level 6 National Referral Hospitals (see Figure 1). In Nairobi County, the public health workforce is estimated to have 3,290 personnel, of which 2,604 (79\%) are technical staff. The technical staff mainly comprise of General Doctors and Specialists $(292 ; 5.8 \%)$ nurses $(1,379 ; 41.9 \%)$, clinical officers $(269 ; 8.2 \%)$, public health officers $(202 ; 6.1 \%)$, and laboratory technologists/technicians $(170 ; 5.2 \%)(25)$. 
Due to the significant communicable and non-communicable disease burden associated with Maternal, Neonatal, and Child Health in Kenya, Nairobi County has enhanced service delivery systems to include and these services were being offered as routine clinics in the two facilities. The county health reports convey that the county is cognizant of the frequency with which these services are offered and how their content influences how clients would use these services. Strengthening service delivery is crucial to the attainment of the County's strategic objectives and health outcomes.

Mental health care must be provided equitably to all populations, including adolescents, who suffer from a lack of tailored interventions and available mental health services. Adolescence is a critical transitional stage in life, and many adolescents experience challenges such as independence, self-identity, family dysfunction, which all contribute to mental illness. Providing youth-friendly services is challenging due to developing physical, emotional, and mental health that requires specifically tailored interventions $(26,27)$. It is crucial to identify gaps in existing services and evaluate the effectiveness of this targeted population.

Three key objectives were guiding our inquiry: a) to map the available health services, cadres, and human resources and development funding partners in the two health centers, b) to assess existing mental health services available in the primary health care centers, and c) to carry out facility-level barriers and facilitators in the two health centers around integration of mental health into routine care with a focus on services targeting adolescents. Through this, we strive to report available services and evaluate both facilitators and challenges in mental health integration under the Kenyan government's efforts towards Universal Health Coverage.

\section{Methods}

\section{Study Design}

We evaluated existing services, cadres, human/ financial resources, and funding partners. Additionally, this data was designed into Key Informant Interview (KIIs) questions to capture SWOT (strengths, weaknesses, opportunities, and threats) based appraisal of the health centers.

Ethical approval

Ethical approval was obtained from the Kenyatta National Hospital and University of Nairobi Ethics and Research Committee (Approval No. P694/09/2018). Permission was obtained from Nairobi County Health Directorate (Approval No. CMO/NRB/OPR/VOL1/2019/04). A research license was also obtained from the National Commission for Science, Technology and Innovation (Approval No. NACOSTI/P/19/77705/28063).

\section{Study Instrument}


This study's primary instrument was the Key Informant Interviews (KIls), using interview guides in which healthcare workers discussed existing services and integration of mental health services, amongst other topics. The interviewees were first presented with a written and oral consent to participate in the study, clearly stipulating the study purposes, procedures, benefits, and risks in which no physical or emotional harm was anticipated. Each interview was conducted by a trained researcher and audio recorded. The key questions that were addressed in the interviews are provided in Table 1. Data was collected using six WHO-AIMS domains that include: 1) policy and legislative framework; 2) organization and integration of mental health services; 3 ) mental health in primary care; 4) human resources; 5) public information and links with other sectors, and 6) monitoring and research. Services-related data was collected from KIls with two (2) facility in-charges using the Nairobi City County Human Resource Health Strategy record forms.

\section{Table 1}

List of questions and probes on Klls

1. What are the types of health services offered at this particular facility? How often do they run?
3. Who provides these services to the patients? Level of education?
Who are they and what kind of support to they provide?
4. When you think about mental health, do you feel that the facility helps the community in that
area?

5. What are some of the barriers and facilitators the facility has in providing mental health services for the population it serves?

6. What do you understand by integrated mental health?

7. What do you think is needed to integrate mental health in $\mathrm{PHC}$ ?

Is it a long term or short-term goal? Could you explain?

8. In your own role as a nurse/technician/Social worker, what adjustments are needed to accommodate mental health services?

9. Do you feel you are equipped to provide services?

10. What would you need to address specific needs for you to offer mental health Services?

11. Do you need - knowledge - please explain what that means?

12. Do you think - attitudes - need changing- please explain what that means?

In addition to KIIs, service data key to this study was obtained using County Human Resource Health forms. The County human resource health form and the KIls were presented to the two facility in-charges of both facilities $(n=2)$, and corroborative information sought from staff members at the two facilities. 


\section{Participants}

To assess personal views on mental health services in primary health care(12) Health Care Workers (HCWs) for this study. The two facility in-charges were selected due to their administrative rank, while the other ten HCWs were picked randomly from different clinics. HCWs included facility in-charges, Antenatal Clinic (ANC) Nurses, Prevention of Mother to Child Transmission (PMTCT) Nurse, child welfare clinic (CWC) nurses, family planning nurse, comprehensive care clinic (CCC) nurse, mentor mother and Community Health Assistant (CHAs). Each HCW was conveniently and privately interviewed in-person from their respective facilities while on duty. Participants were probed about their views on the importance of mental health services in their facilities and their knowledge and exposure to the field of mental health in primary health care services.

\section{DATA ANALYSIS}

As we had embedded the six WHO-AlMs domains into the KII questions to capture the services, cadres, and supportive bodies at the two facilities in our analysis, we aimed to determine the barriers and facilitators in delivering mental health services. To accurately identify these indicators, our research team utilized the SWOT analysis that looked at the barriers (weaknesses and threats), facilitators (strengths and opportunities), and capacity-building needs for mental health integration in primary health centers.

All the twelve (12) enrolled HCWs participated in interviews. Audio recordings of interviews with HCWs were transcribed verbatim, transcribed from Kiswahili to English, and analyzed. One researcher from our research team read each transcription and manually coded data into various themes based on interview content (i.e., barriers to integrating mental health services, necessary training, and HCW attitudes). Other researchers in the team performed a secondary review of themes and consulted to resolve any coding conflicts. Results are determined from data from the twelve (12) transcripts. Themes for barriers and facilitators in mental health services are supported by illustrative quotes, as seen below. Participant names and other identifying information have been changed for confidentiality reasons.

\section{Results}

\section{Demographics}

Of the twelve (12) health care workers enrolled in the study, ten (10) were females and two (2) males. The oldest participant was aged 55 years, while the youngest was 36 years. Half of the participants were nurses six (6), two (2) clinical officers, one (1) psychiatric clinical officer, two (2) community health assistants, and one (1) community-based mentor mother. Eight (8) of the participants were recruited by the Ministry of Health, while three (3) were recruited by external funding partners representing clinics such as Prevention of mother-to-child transmission, antenatal clinic, child welfare clinic, family planning, and psychiatric clinics. 


\section{Staffing}

A total of fifty-one (51) staff members worked at the Kangemi health center, while forty-one (41) staff members were at the Kariobangi health center. In both facilities, seven (7) staff members were supported by partners staff who assisted with additional service coverage. The two facilities had at least three psychiatric health care workers - one nurse at Kangemi health center and two Psychiatric Clinical Officers at the Kariobangi health center - trained to manage mental health-related challenges. Personnel at the health centers were either $\mathrm{MOH}$ or external partner organizations employees. Despite both health centers being externally funded, the Kangemi health center had forty (40) MOH staff and eleven (11) partner supported staff, while Kariobangi health center had twenty-seven (27) and sixteen (16) staff, respectively. The Kangemi health center had more staff than the Kariobangi health center, despite both facilities serving an almost similar population, 59,000 and 65,039, respectively.

\section{Services}

In both facilities, clinics were running five days a week except for the hospital's psychiatric clinic once a week. Services are limited, with maternity services being offered only in the Kangemi health center, and youth-friendly services are not emphasized in either clinic. Also, these community health facilities provide several services for nearby populations. These services include tuberculosis, antenatal and maternity, family planning, child welfare clinics, Comprehensive Care Clinic and HIV testing (HTS), laboratory, nutrition, and immunization. We found that three to four clinics ran lower frequency clinics than usual five days per week due to staffing issues. For instance, both facilities' psychiatric clinic is held once a week and managed by outsourced staff from Kamili Organization. The non-communicable disease (NCD) clinic is held weekly at Kangemi and bi-weekly at Kariobangi Health Center and provides services on managing and preventing diabetes, hypertension, and cancer. While male health services in Kangemi are infrequent, the Kariobangi center offers a dedicated service where some male CHV help the male patients with their medical requirements. Health care workers reported that they made various efforts to engage with youth by tailoring services by providing them with unique slots for sexual and reproductive health and HIV services. Using the clinic entrance proved to be a source of shelter and a haven for many young women and adolescents who were homeless or exposed to violence and abuse. Despite several attempts at engaging youth, we did not see many well-developed youth-friendly services in either facility.

We found that many of the services were outpatient, running from 0800hours to 1700 hours except for the maternity services at Kangemi Health Center, which operated throughout (24 hours all days of the week). The services are run by clinical officers, nurses, laboratory technicians, while the community health assistants (CHAs) and community health volunteers (CHVs) actively escort patients to these services. These are high numbers of undiagnosed patients and unattended to mental health services from what we learned from our engagement. The numbers that are seen can quickly become a source of strain given that very few health care providers offer these services.

\section{Support}


The Kangemi Health center has been receiving external funding from Afya Jijini (USAID), Aids Healthcare Foundation (Japan), Malteser, Jhpiego, Kamili Organization, and the national level support from the Nairobi City County and the Ministry of Health $(\mathrm{MOH})$. The Kariobangi Health center similarly has been receiving external funding support from Afya Jijini (USAID), AIDS Healthcare Foundation (Japan), Concern Worldwide, MSF (France), and the national level support from Nairobi City County and the Ministry of Health. Community mental health expertise is offered from both the Mathari National Training and Referral Hospital and Kamili Organization, an NGO specializing in training nurses in mental health care for outpatients. Many of these services combined integrated sexual and reproductive health services, youth-focused and mental health services.

\section{Systemic Barriers}

\section{Lack of Integrated Services}

While discussing barriers on a systemic level, participants identified a lack of integrated services as a hindrance to improving mental health outcomes. Staff conveyed various resource and infrastructure challenges such as:

"- okay like the-the-the integration of family planning you know previously family planning-family planning-we have family planning room in outpatient so our clients we used to send them there so they integration is not a bad thing of family planning it is good since our clients will not queue again you know but the room is not-is not convenient to provide the service like you see we don't have water, we don't have sink yes, so hygiene is an issue and we don't have a couch as you can see for you to give an implant you have to-the patient has to be on bed on a couch so it limits-it limits our capacity to-to provide the service so you see the management will take it as if we are rejecting or we are rejecting the change but it is- it is not-they have to act on those things before we go ahead because we are only giving injection and if you talk to a client and she decides that she wants implant you know you will not convince them that let me give an injection because that is what I can give I told them I will just be sending them until we do one two three things [some silence] but it is a good thing [some silence]."...... "The other policy is for the-the-the CCC and PMTCT to give drugs, pharmacy is incorporated in our [laugh]." Female Nurse, KG

\section{Another provider described how implementing integrated medical services within healthcare would be vastly significant:}

"Integration is when we incorporate mental health care into all service points like when someone comes to my clinic he/she is able to be screened for mental health and just the same way we are doing with TB as in every work station somewhere even from the gate the soldier can screen and know that this is a person with depression or stress or what and they may be able to assist them in a way or another. So that is the integration that-that mental health that someone-any client is able to be screened for mental health 
issues at every workstation facility". Reason "Yes, because previously people used to feel like mental health is-they used to stigmatize the mental health and they used to attach it to people who are mad they are in Mathari but mental health issues start from- as in with us even us the health care workers could be struggling with mental health issues and we transfer them to our clients, so it is very important when from really primary health care everyone is so conscious about their own mental health so that even as they take care of clients, they are sober and they give quality care and just to protect them from those clients from having bigger issues of mental health like depressions." Female Nurse, KG

\section{Lack of Support}

Another area of concern was the lack of support for mental health services. Below, participants mention the need for more significant support from partner and donor agencies:

"it's my prayer that the partners they have on board may implement because most of these health partners who come on board they are either on a research or maybe they are just passing by for one or two issues then they end the support. It is my prayer that if we may get more of the support and also if they can impart more knowledge to the health providers given the different clinics I think this may be of help, because I may attest as a person that since you came on board I am able to serve my clients better than I was previously. So I would like also maybe the same knowledge to be imparted to the other health providers and we may see ways of sustaining the same just by the knowledge, if you give us a lot of knowledge we may look for ways of sustaining the same services in this clinic and for the benefit of our clients; as I know most of our clients as we interact with them we see that they have issues that really need to be sorted out and I think this is one of the areas where we meet like every other person in the community; here in the health center, yes. But thank you very much for the much that you have done "- Female HCW, KG

\section{Privacy Concerns}

Many healthcare workers highlighted issues of privacy and feeling that their facility lacks appropriate visual and auditory privacy:

"Yes. We lack-I think in terms of rooms and because sometimes you just find that the counselor is outside with a client talking so you know even for the-for you to capture the concentration of that client is a challenge, because the client may see somebody whom he/she knows at stares at him/her so and you need a quiet room and also privacy and confidentiality of a client is very important" Male Nurse, KR

"We need a room, a permanent room for psychiatric clinic, with all the drugs stored there with a permanent staff there specifically to deal with psychotic patients and psychotic issues" Male Nurse, KR

\section{a) Social Barriers}




\section{Culture and Stigma}

Participants also talked about social barriers in terms of cultural beliefs and stigma surrounding mental health that need to be urgently addressed. One nurse expressed difficulty addressing mental disorders to a patient with a different cultural belief:

“Because there are some cultures where people don't even go to hospital when they are sick; they believe in prayer. So such like when you meet such a patient it will be hard to convince this client to come to the facility because he has a belief that if a $t$ all he can be prayed for he will be healed. In attitude you know there are those staffs who normally take that in psychiatry we are dealing with mental issues, it can just be a minor medical issue or a major or something you can handle even not using drugs, something you can come maybe talk with the patient not a must he or she ends up taking drugs ...These beliefs you know most of the youths they have that mentality that when you are stressed you end up using drugs that it reduces stress; something like that. When you have family issues maybe with your wife and you have an issue you end up taking drugs or alcohol so that you feel like you are relieved" Male Nurse, KR

\section{b) Individual Barriers}

\section{Attitudes and Behavioral Issues in HCWs}

The first barrier that health facility workers identified has to do with their jobs. HCWs described that a change in provider attitude and behavior is essential to improving health services. One provider commented on the necessity for change:

"- - we need to change because for example like an adolescent who is having HIV there is still stigma even within the staff members, after the client has come they are like "that girl and the way she is young, where did get HIV from..." Female, HCW, KG

\section{Another provider described how she is already changing her approach towards clients to improve trust levels:}

"I must say that to some extent your team has also helped us to realize that some of our attitudes will make the client either to open up or not to open up. So very true and I must say for the last three or so months I am experiencing some changes; now that we have interacted with your team we are able to approach these clients in a better way that will enable them come very close to us as compared to the previous times whereby they could share just a little bit then maybe reserve the major - -." Female HCW, KG 


\section{Other providers shared how good attitudes held by health care workers could positively impact their patients' outcomes:}

"Yes; there has been a good rapport of late and one of the areas, maybe I can point out one area; we have group sessions and during the group sessions we start ourselves by giving our experiences and given the experiences we also allow them the space to come in and share what they think we can do better to help them and this one has enabled clients to open up especially in the groups and for those who seem to be a little bit reserved we have also given them the space on a one on one interaction and things are working better. So it is a plus, for the last three months yes we are seeing different results from the clients and also from the health providers" Female HCW, KG

\section{Lack of Training}

Only three participants among the two facilities had psychiatric training, with one participant who had a psychiatric diploma. The remaining HCWs reported being exposed to mental health topics back in-school training, yet; all participants equivocally shared that their previous exposure was limited. Below, a nurse describes her work set up and desire to receive further mental health exposure:

'We would love to learn more about mental health. Basically, most of the people have gone through; like for the nurses and clinical officers they have gone through the basic training on psychiatry. The normal; the basics but there is more into the diagnosis - - so when it comes to knowledge people just; people are not very well acquainted with how to identify early. Mostly we only think the psychiatric people are people who have reached a point where already they are maybe talking to themselves; you can see the psychiatry condition physically. But we are not yet at that level of identifying the psychiatric condition just by interviewing" Female Nurse, KR

\section{A common theme regarding the necessity for more exposure and better education surrounding mental health was stressed throughout various interviews. One nurse describes the importance of integration of services and proper mental health training:}

"To integrate the mental health [Silence] I think it is training of staff so that when for example it's on a Friday and a mental health client comes; I am able to do the counseling, I am able to cater for his problems and in the process if I find that he has another problem I take care of it" Female nurse, KR

Other participants discussed learning new skills that could help them engage with their clients better. Providers echoed a shared struggle to get their clients to open up due to communication barriers that impacted help-seeking behaviors. Below, providers talk about the benefits of having an orientation or classes concerning their role: 
"I may say to some extent yes I've been given some information though I may not say I am fully baked for the position I believe given a chance probably some orientation or maybe a class or two I may be more empowered to handle the clients, but tentatively basically the knowledge l've acquired from your team I believe at this juncture I may be able to look at a client and tell that this client is not in the same mood probably like I saw them in the previous session. I may be able to detect one or two things that may be an indicator that this client needs some mental health care session." Female HCW, KG

\section{Another participant emphasized adequate training would be able to provide staff with the confidence of providing hands-on support and timely care:}

"Okay, maybe just basically I would say refresh a bit and also some little empowerment on the same because there are those who get a little bit reserved so you may not be able to take it out from them. There are those who are a bit adamant; maybe the skill of how to go about it I believe I may need to be orientated on that to be able to get through to this client to open up" Female HCW, KG

\section{Discussion}

This study aimed to map the available health services, assess existing mental health services available in the primary health care centers, and identify factors impacting the integration of mental health into routine care, focusing on services targeting adolescents. We found that each health facility provided free health services, daily outpatient services, weekly mental health services, and weekly clinics (i.e., NCD clinic). Despite having these services offered, each health facility lacked appropriate knowledge of policy and standard protocols for mental health care, public information, and links with other sectors and monitoring and research. Through in-depth interviews and service data, we identified a significant gap in training and, thus, providing quality and extensive mental health services to patients. As shown in Table 1 , our interviews consisted of set questions that were asked to critical providers. We found out that our participants were well aware of integrating mental health services into routine care. They expressed limited knowledge about mental health disorders due to various individual, social, and systemic barriers akin to findings from a study carried out in South-west Ethiopia among primary health care workers (28).

Barriers included lack of time, space, and resources to roll out quality mental health services, lack of mental health trained personnel, and limited funding to promote mental health education and integrate mental health services within healthcare. Most of our findings were similar to a similar study by Mutiso et al. (29) in Makueni county. We did learn from our participants that they had received which needed further strengthening. The lack of staff training poses a challenge since clinical officers and nurses are the first contacts for clients and adolescents. Findings from a study conducted in Zambia among primary health care workers showed that health care workers noted increased training as the key to integrating mental health in primary care for early identification and management of mental disorders (10). The dearth of knowledge and clinical procedures limits screening, diagnosis, treatment, referral of patients. 
We also found that burnout was reported due to the shortage of facility staff, yet the patient turn-up in the facilities is high. Our findings demonstrate a need to increase human resources capacity and health system's capacity to achieve the Kenyan targets for preventive and promotive mental health services. Similar findings were recorded in a study carried out by Jenkins et al. (19) on health systems challenges to integrating mental health delivery in primary care in Kenya. Their findings recorded barriers such as workload and shortage of trained staff (19). Clinics must be adequately staffed to implement mental health services in $\mathrm{PHC}$, with trained professionals to identify early, diagnose and treat health problems. As evidence, lack of proper training limits the number of patients that clinics can provide care to. Health facilities should lobby for mental health investment to avoid DALYs of its people living with mental health problems which in the long term is an economic burden to the country. Mental health problems are a global situation but can be resolved by the community level's resources. There is a need to map other facilities and use the study conclusions to implement mental health policies and evidence-based mental health interventions that reduce, prevent, and promote mental health throughout the county and country. It is essential that further research investigates ways to improve the proper training for mental health care, increase health facility staffing, finance mental health programs, better provider self-care training, and enhance the supervision and appropriate referral pathways.

There are well-developed mental health plans and well-identified indicators to improve mental health care on both county and national levels. This treatment gap continues to perpetuate the increasing disease burden, and thus, addressing these problems is essential to disease prevention. While health system strengthening approaches have been embraced by health reforms in Kenya, services are not currently providing equal and quality to vulnerable populations. For example, little has been done to increase the budget and add human resources to combat the increasing burden of mental illnesses that mainly target adolescents. An integrated health care model would look at unified use of protocols, plans, and teamwork to care for the populations in both medical and mental service management terms. As shown in Figure 1 of the structure of healthcare in Kenya, our mapping exercise demonstrated the urgent need to develop collaborative care models to embed mental health services with the ultimate goal of integrating mental health services. Through the interviews, various health providers understood the meaning of integrated services and the urgency of this goal; however, they believed integration was a long-term goal rather than a short-term goal. Integrating mental health services in the current systems would ensure that communities and the health center patients maximize service benefits. It is essential to invest in quality health infrastructures, such as health equipment, information, and communication technology, and transport to allow better care and referral dimensions in primary health care. Improving guidelines and policies for mental health provision and correct information to reduce health care attitudes and discrimination related to mental health is imperative. This improvement can be achieved by training healthcare providers to assess mental disorders early on, create safe spaces in facilities, and utilize community health volunteers who can support adolescents in their respective communities. Improvements to health services are only possible if they are written and implemented at the policy level. The third level is the organization, where the political and economic are identified and sorted through decision-making systems, operating systems, or human resource systems. The financial, administrative, 
human resource, and practical clinical approaches are created to coordinate the providers' activities at level two. Currently, the government offers free medical services in health facilities with minimal Insurance coverage of mental health problems. Towards improving access and availability of quality services, efforts need to be streamlined with ongoing universal health coverage programs.

Our study's limitations include lack of generalizability as participants were picked specifically during their free hours at work from only two facilities out of the total twelve facilities. As opinions regarding mental health service delivery and importance may vary between people, our analysis may not represent the consensus. Also, our data analysis is purely qualitative, and our study does not include a quantitative component- posing another threat to external validity.

\section{Conclusion}

This study aims to integrate mental health services in primary health care for all but especially the adolescent peripartum population in the LMIC context. Implementation has been hampered by a lack of financial and trained human resources and social barriers. Our report also highlights various mental health service improvements over the past few years, including increased services and collaboration between partner organizations.

Literature underlines that peripartum adolescents are faced with multiple adverse and high-risk exposure that makes them vulnerable to mental health problems, highlighting the need to integrate youth-friendly tailored, timely and comprehensive mental health services with routine care. Future research should investigate the implementation of an integrated care model to reduce the mental health treatment gap at the primary care level, specially tailored to peripartum adolescents seeking mental health care.

\section{Abbreviations}

UHC- Universal Health Coverage

CHA-Community Health Assistant

$\mathrm{MOH}-$ Ministry of Health

PHC- Primary Health Care

WHO- World Health Organization

DALYs- Disability Adjusted Life Years

SSA-Sub-Saharan Africa

Page 15/21 
YLDs- Years Lived with Disabilities

WHO AIMS- World Health Organization Assessment Instrument for Mental Health Systems

LMICs- Low and Middle-Income Countries

WHO mhGAP- Mental Health Gap Action Program

CCC- Comprehensive Care Clinic

T.B- Tuberculosis

CDF- Constituency Development Fund

HCW- Health Care Workers

ANC- Antenatal Clinic

PMTCT- Prevention of Mother to Child Transmission

PESTLE- Political, economic, Social, Technology, Legal and Environment Framework

HIV- Human Immunodeficiency Virus

HTS- HIV testing Services

NCD-Non-Communicable Diseases

CBO-Community Based Organizations

ICT- Information and Communications Technology

CHW- Community Health Workers

MSF- Medecines Sans Frontieres

FIC/NIH- Fogarty International Center of the National Institutes of Health

HRH- Nairobi City County Human Resource Health Strategy

GOK- Government of Kenya

\section{Declarations}

Ethics approval and consent to participate: 
the study was approved by the Kenyatta National Hospital/University of Nairobi ethical review committee (approval no. P694/09/2018). The study received approval from the Nairobi county health directorate (approval no. CMO/NRB/OPR/VOL1/2019/04) and approval from National Commission for Science, Technology, and Innovation (NACOSTI/P/19/77705/28063). The consent to participate would be sought from all study participants, including stakeholders and advisory committee members from whom data would be collected.

\section{Consent for publication:}

all study participants gave their consent to publish this work's findings.

\section{Availability of data and material:}

NIMH-funded research requires the data to be made available for further studies, and this would be the case in this work. All the personal information would be de-identified, and the data put on excel sheets for research use. Some interview transcripts would be kept by the researcher and may be shared on reasonable request.

\section{Competing interests:}

the authors do declare that they do not have any competing interests

\section{Funding:}

Research reported in this publication was supported by the Fogarty International Center of the National Institutes of Health under Award Number K43TW010716. The content is solely the authors' responsibility and does not necessarily represent the National Institutes of Health's official views. The first author was funded by the Fogarty Foundation K43 grant (2018-2023), and the co-authors are her mentors, collaborators on this study.

\section{Authors' contributions:}

MK developed this paper, data collection was by $\mathrm{KM}, \mathrm{VN}$, and BM while $\mathrm{BA}, \mathrm{OG}, \mathrm{GNW}, \mathrm{NK}$, SS guided on appropriately conceptualizing the study topic and the various policy frameworks that the country has adopted in the past.

\section{Acknowledgments:}


The authors would like to thank the Nairobi county health directorate, Ministry of Health, UNFPA, WHO Kenya country office, Kariobangi, and Kangemi health facility staff.

\section{References}

1. WHO. World health statistics 2019: monitoring health for the SDGs, sustainable development goals [Internet]. Geneva PP - Geneva: World Health Organization; 2019. Available from: https://apps.who.int/iris/handle/10665/324835

2. World Health Organization. Mental health action plan 2013-2020 [Internet]. 2013. Available from: https://apps.who.int/iris/handle/10665/89966

3. Neisi leila, Riahi leila, Komeili A, Bolhari J. A review of the world health organization assessment instrument for mental health system: WHO-AIMS. Q J Nersing Manag. 2018;6(3):66-77.

4. World Health Organization. WHO | Comprehensive mental health action plan 2013-2020 [Internet]. WHO. World Health Organization; 2013 [cited 2019 Dec 20]. 48 p. Available from: https://www.who.int/mental_health/action_plan_2013/en/

5. Saxena S, Lora A, van Ommeren M, Barrett T, Morris J, Saraceno B. WHO's Assessment Instrument for Mental Health Systems: Collecting Essential Information for Policy and Service Delivery. Psychiatr Serv [Internet]. 2007 Jun;58(6):816-21. Available from: http://psychiatryonline.org/doi/abs/10.1176/ps.2007.58.6.816

6. Gouda HN, Charlson F, Sorsdahl K, Ahmadzada S, Ferrari AJ, Erskine H, et al. Burden of noncommunicable diseases in sub-Saharan Africa, 1990-2017: results from the Global Burden of Disease Study 2017. Lancet Glob Heal [Internet]. 2019 Oct;7(10):e1375-87. Available from: https://linkinghub.elsevier.com/retrieve/pii/S2214109X19303742

7. Charlson FJ, Diminic S, Lund C, Degenhardt L, Whiteford HA. Mental and substance use disorders in Sub-Saharan Africa: predictions of epidemiological changes and mental health workforce requirements for the next 40 years. PLoS One [Internet]. 2014;9(10):e110208. Available from: http://www.ncbi.nlm.nih.gov/pubmed/25310010

8. Murray CJ, Lopez AD, Jamison DT. The global burden of disease in 1990: summary results, sensitivity analysis and future directions. Bull World Health Organ [Internet]. 1994;72(3):495-509. Available from: http://www.ncbi.nlm.nih.gov/pubmed/8062404

9. Kohn R, Saxena S, Levav I, Saraceno B. The treatment gap in mental health care. Bull World Health Organ [Internet]. 2004 Nov;82(11):858-66. Available from: http://www.ncbi.nlm.nih.gov/pubmed/15640922

10. Mwape L, Sikwese A, Kapungwe A, Mwanza J, Flisher A, Lund C, et al. Integrating mental health into primary health care in Zambia: a care provider's perspective. Int J Ment Health Syst [Internet]. 2010 Jul 25;4:21. Available from: http://www.ncbi.nlm.nih.gov/pubmed/20653981

11. Chisholm D, Docrat S, Abdulmalik J, Alem A, Gureje O, Gurung D, et al. Mental health financing challenges, opportunities and strategies in low- and middle-income countries: findings from the 
Emerald project. BJPsych open [Internet]. 2019 Aug 6;5(5):e68. Available from: http://www.ncbi.nlm.nih.gov/pubmed/31530327

12. lemmi V. Sustainable development for global mental health: a typology and systematic evidence mapping of external actors in low-income and middle-income countries. BMJ Glob Heal [Internet]. 2019;4(6):e001826. Available from: http://www.ncbi.nlm.nih.gov/pubmed/31908860

13. Kiima D, Jenkins R. Mental health policy in Kenya -an integrated approach to scaling up equitable care for poor populations. Int J Ment Health Syst [Internet]. 2010;4(1):19. Available from: http://ijmhs.biomedcentral.com/articles/10.1186/1752-4458-4-19

14. Ndetei DM, Khasakhala LI, Kuria MW, Mutiso VN, Ongecha-Owuor FA, Kokonya DA. The prevalence of mental disorders in adults in different level general medical facilities in Kenya: a cross-sectional study. Ann Gen Psychiatry [Internet]. 2009;8(1):1. Available from: http://annals-generalpsychiatry.biomedcentral.com/articles/10.1186/1744-859X-8-1

15. Forum on Neuroscience and Nervous System Disorders; Board on Health Sciences Policy; Board on Global Health; Institute of Medicine; National Academies of Sciences, Engineering and M. Providing Sustainable Mental and Neurological Health Care in Ghana and Kenya [Internet]. Norris SP, Forstag EH, Altevogt BM, editors. Washington, D.C.: National Academies Press; 2016. Available from: http://www.nap.edu/catalog/21793

16. KNBS. 2019 Kenya Population and Housing Census Volume 1: Population by County and SubCounty [Internet]. Vol. I, 2019 Kenya Population and Housing Census. 2019 [cited 2021 Feb 12]. 49 p. Available from: https://www.knbs.or.ke/?wpdmpro=2019-kenya-population-and-housing-censusvolume-i-population-by-county-and-sub-county

17. Kakuma R, Minas H, van Ginneken N, Dal Poz MR, Desiraju K, Morris JE, et al. Human resources for mental health care: current situation and strategies for action. Lancet [Internet]. 2011 Nov;378(9803):1654-63. Available from: https://linkinghub.elsevier.com/retrieve/pii/S0140673611610933

18. Bitta MA, Kariuki SM, Chengo E, Newton CRJC. An overview of mental health care system in Kilifi, Kenya: results from an initial assessment using the World Health Organization's Assessment Instrument for Mental Health Systems. Int J Ment Health Syst [Internet]. 2017 Dec 17;11(1):28. Available from: http://ijmhs.biomedcentral.com/articles/10.1186/s13033-017-0135-5

19. Jenkins R, Othieno C, Okeyo S, Aruwa J, Kingora J, Jenkins B. Health system challenges to integration of mental health delivery in primary care in Kenya- perspectives of primary care health workers. BMC Health Serv Res [Internet]. 2013 Dec 30;13(1):368. Available from: https://bmchealthservres.biomedcentral.com/articles/10.1186/1472-6963-13-368

20. Mutiso V, Warsame AH, Bosire E, Musyimi C, Musau A, Isse MM, et al. Intrigues of Accessing Mental Health Services Among Urban Refugees Living in Kenya: The Case of Somali Refugees Living in Eastleigh, Nairobi. J Immigr Refug Stud [Internet]. 2019 Apr 3;17(2):204-21. Available from: https://www.tandfonline.com/doi/full/10.1080/15562948.2018.1433904 
21. WHO. WHO Mental Health Gap Action Programme (mhGAP). Who [Internet]. 2018 [cited 2020 Mar 13]; Available from: https://www.who.int/mental_health/evidence/mhGAP/en/

22. Muga FA, Jenkins R. Health care models guiding mental health policy in Kenya 1965 - 1997. Int J Ment Health Syst [Internet]. 2010 Apr 28;4(1):9. Available from: http://www.ncbi.nlm.nih.gov/pubmed/20426855

23. Jenkins R, Kiima D, Okonji M, Njenga F, Kingora J, Lock S. Integration of mental health into primary care and community health working in Kenya: context, rationale, coverage and sustainability. Ment Health Fam Med [Internet]. 2010 Mar;7(1):37-47. Available from: http://www.ncbi.nlm.nih.gov/pubmed/22477921

24. Wright J, Health Finance \& Governance Project. Essential Package of Health Services Country Snapshot: Kenya. 2015;(July):34. Available from: https://www.hfgproject.org/essential-package-ofhealth-services-country-snapshot-kenya/

25. County Government. Nairobi City County Health Sector Strategic and Investment Plan. 2017;2019(Revised 2017):1-71.

26. WHO. 2014 Mental Health Atlas [Internet]. Geneva, Switzerland; 2015. 69 p. Available from: http://www.who.int/mental_health/

27. WHO. WHO | Mental Health ATLAS 2017 [Internet]. WHO. World Health Organization; 2018 [cited 2020 Mar 13]. p. 68. Available from: https://www.who.int/mental_health/evidence/atlas/mental_health_atlas_2017/en/

28. Abera M, Tesfaye M, Belachew T, Hanlon C. Perceived challenges and opportunities arising from integration of mental health into primary care: a cross-sectional survey of primary health care workers in south-west Ethiopia. BMC Health Serv Res [Internet]. 2014 Dec 6;14(1):113. Available from: http://bmchealthservres.biomedcentral.com/articles/10.1186/1472-6963-14-113

29. Mutiso VN, Musyimi CW, Gitonga I, Tele A, Pervez R, Rebello TJ, et al. Using the WHO-AIMS to inform development of mental health systems: the case study of Makueni County, Kenya. BMC Health Serv Res [Internet]. 2020 Dec 20;20(1):51. Available from: https://bmchealthservres.biomedcentral.com/articles/10.1186/s12913-020-4906-3

\section{Figures}




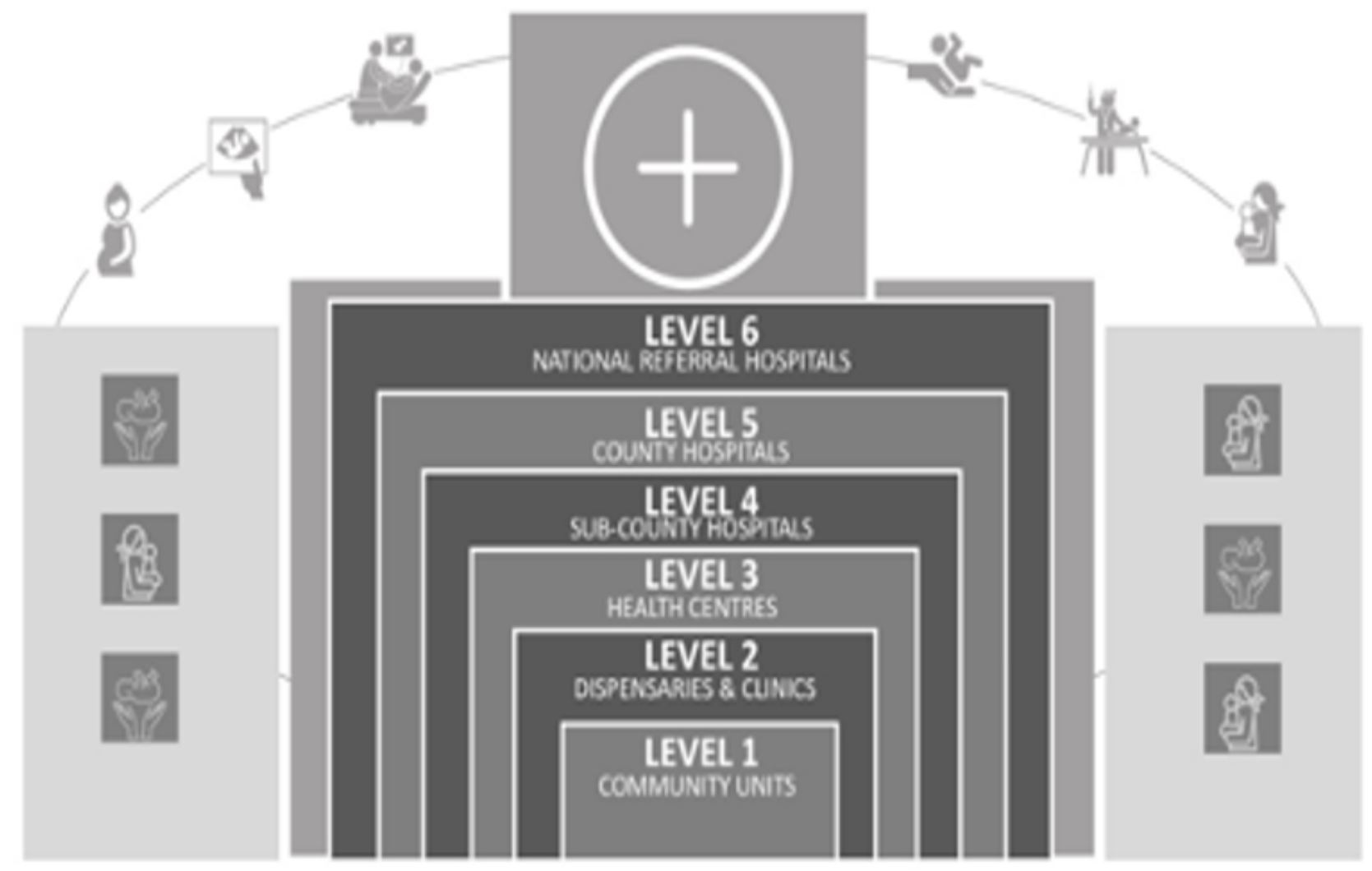

Figure 1

Healthcare structure in Kenya 